\title{
Gespiegelte Gesundheitslandschaft - oder wenn die SÄZ traurig macht
}

Kürzlich erhielten wir die Zuschrift eines Kollegen, der festhielt, er lese die SÄZ zwar regelmässig, aber die Lektüre stimme ihn häufig traurig, da der Inhalt der Zeitschrift seine Wertvorstellungen und medizinischen Ideale immer weniger widerspiegle. Nun könnte man als Redaktion eine solche Mitteilung zur Kenntnis nehmen und zur Tagesordnung übergehen: schliesslich weiss jeder Medienschaffende, dass man es trotz aller Bemühungen nie allen recht machen kann.

Die Aussage des Kollegen ist es aus meiner Sicht aber wert, näher betrachtet zu werden. Zum einen fällt auf, dass er die SÄZ offenbar regelmässig liest. Diese für uns als Redaktion erfreuliche Tatsache ist insofern bemerkenswert, als der Kollege an etwas festhält, das für ihn in vielen Fällen nicht sehr erbaulich ist und offenbar im Verlauf der Jahre zunehmend unerfreulicher wurde. In diesem Verhalten scheint sich eine Verbundenheit mit «der Sache der Ärzteschaft», ein Engagement zu manifestieren, das über das reine Lustprinzip hinausgeht, ähnlich wie bei einer Partnerschaft, zu der man auch in schwierigen Zeiten steht. Zum anderen ist es sehr ungewöhnlich, dass jemand seine Traurigkeit über Inhalte der SÄZ bekundet. Als Redaktion sind wir häufig mit Ärger oder gar Wut unserer Leserschaft konfrontiert - die Leserbriefspalten könnten gewissermassen ein Lied davon singen. Ärger will wahrgenommen werden, sich Luft verschaffen, während Trauer - zumindest in unserem Kulturkreis - sich tendenziell zurückzieht, verschliesst. Um so stärker ist die Wirkung, wenn sie sich doch einmal nach aussen wendet.

Zur Einordnung einer solchen Reaktion scheint es mir angezeigt, die Funktion der SÄZ für die Ärzteschaft und innerhalb der gesundheitspolitischen Landschaft unseres Landes anzusprechen. Da ist zunächst die Rolle, die die SÄZ als offizielles Organ der FMH spielt. Die Tatsache, dass Auseinandersetzungen im Gesundheitswesen mit zusehends härteren Bandagen geführt werden, bekommt auch unsere Standesorganisation zu spüren. Von ihr wird gewissermassen die Quadratur des Kreises verlangt: Sie soll zunächst die teilweise stark divergierenden Interessen der Ärzteschaft unter einen Hut bringen, diese dann mit kompromissloser Durchschlagskraft gegen aussen vertreten und gleichzeitig politisch rea- lisierbare Lösungen anstreben. In vielen Fällen schier unmöglich - und da die FMH um Transparenz bemüht ist, in (fast) allen Stadien in der SÄZ zu verfolgen. Die nachfolgende Empörungslawine inklusive, siehe das Kapitel «Dringlichkeitspauschale».

Zum anderen ist die SÄZ eine offene gesundheitspolitische Plattform, die aktuelle Diskussionen und auch Kontroversen im Gesundheitswesen aufgreifen und abbilden soll. Etliche der gegenwärtigen Tendenzen sind für die Ärzteschaft in ihrer überwiegenden Mehrheit unerfreulich und können einen in der Tat traurig stimmen. Stichworte dazu sind Ökonomisierung, Bürokratisierung, Elektronisierung - für viele ist die Medizin in den Sog einer eigentlichen «Entmenschlichungsmaschinerie» geraten. Mit den Idealen, um derentwillen man einst diesen Beruf wählte (oder dies im nachhinein zumindest so sehen will), haben solche Entwicklungen oft wenig bis gar nichts zu tun. Dennoch muss man sich der Realität stellen, insbesondere dann, wenn man Verbesserungen anstrebt. Als Redaktion setzen wir zwar mit eigenen Beiträgen dosiert thematische Schwerpunkte. Grundsätzlich fühlen wir uns aber verpflichtet, das ganze Spektrum der Meinungen und Standpunkte zu wichtigen Fragen des Gesundheitswesens möglichst unvoreingenommen wiederzugeben, damit sich unsere Leserinnen und Leser selbst ein fundiertes Urteil bilden können.

Und damit unsere Leserschaft - in erster Linie Ärztinnen und Ärzte - die Möglichkeit hat, zu reagieren, selbst aktiv zu werden. Zum Beispiel durch eigene Beiträge in der SÄZ, deren Artikel zu einem substantiellen Teil von unseren Leserinnen und Lesern stammen. Entsprechende Gefässe wie zum Beispiel die Rubrik Tribüne, die der freien Meinungsäusserung dient, stehen zur Verfügung - und sie werden auch genutzt.

Die langfristig wahrscheinlich beste Möglichkeit, die SÄZ von traurigen Inhalten zu befreien, ist wohl ein entschlossenes Engagement für die Anliegen der Ärzteschaft, für eine gute und menschengerechte Medizin. Denn eine erfreuliche gesundheitspolitische Landschaft wird sich ohne Zweifel in der SÄZ widerspiegeln.

Bruno Kesseli 